\title{
EFEITO DE PLANTAS INSETICIDAS NO COMPORTAMENTO E BIOLOGIA DE PLUTELLA XYLOSTELLA (LEPIDOPTERA: PLUTELLIDAE)
}

\author{
F.G. de Jesus', L.A. de Paiva ${ }^{2}$, V.C. Gonçalves², M.A. Marques², A.L. Boiça Junior ${ }^{3}$ \\ ${ }^{1}$ Instituto Federal Goiano, Rod. Prof. Geraldo Silva Nascimento, km 2,5, CEP 75790-000, Urutaí, GO, Brasil. \\ E-mail: fgjagronomia@zipmail.com.br
}

RESUMO

\begin{abstract}
Avaliou-se o efeito de Azadirachta indica A. Juss. (Nim), Sapindus saponaria L. (Sabão de soldado), Nim + Piretro + Rotenona, Dimorphandra mollis (Faveira) e Stryphnodendron adstringens (Mart) Coville (Barbatimão) em relação a não-preferência para oviposição e alimentação, atratividade e biologia de Plutella xylostella. Discos foliares de couve (Brassica oleracea var. acephala) cultivar Manteiga foram imersos em cada extrato à concentração de 10\% (massa/volume) por 30 segundos para realização dos experimentos. Para o teste sem chance de escolha, os tratamentos que apresentaram menores atratividades foram os extratos de $A$. indica e $D$. mollis, e o menor consumo foi em $A$. indica. Os extratos de $A$. indica, $S$. saponaria $D$. mollis e $S$. adstringens proporcionaram efeito deterrente na oviposição de $P$. xylostella. Os tratamentos $A$. indica, S. saponaria e S. adstringens influênciaram negativamente os parâmetros biológicos da praga.
\end{abstract}

PALAVRAS-CHAVE: Traça-das-crucíferas, brássicas, planta inseticida, MIP.

\begin{abstract}
EFFECT OF INSECTICIDAL PLANTS ON THE BIOLOGY AND BEHAVIOR OF PLUTELLA XYLOSTELLA (LEPIDOPTERA: PLUTELLIDAE). The effect of aqueous extracts of Azadirachta indica A. Juss., Sapindus saponaria L., Nim + Piretro + Rotenona, Dimorphandra mollis and Stryphnodendron adstringens (Mart) Coville was evaluated in relation to non-preference for oviposition and feeding, attractiveness and biology of Plutella xylostella. For the experiment, leaf discs from cabbage (Brassica oleracea var. acephala) plants of the Butter cultivar were immersed in each extract at the concentration $10 \%$ (weight/volume) for 30 seconds. For the no-choice test the treatments that presented less attractiveness were the extracts of $A$. indica and D. mollis, and the consumption was lower in A. indica. The extracts of A. indica, S. saponaria, D. mollis and S. adstringens provided a deterrent effect on oviposition of $P$. xylostella. The treatments A. indica, S. saponaria and S. adstringens showed a negative effect for the biological parameters of the pest.
\end{abstract}

KEY WORDS: Diamondback moth, brassica, insecticidal plants, IPM.

\section{INTRODUÇÃO}

A couve, Brassica oleracea var. acephala (L.), destaca-se entre as plantas hortícolas como um dos alimentos importantes na nutrição humana, sendo rica em minerais e vitaminas (FILGUEIRA, 2008). É uma cultura danificada por diversas pragas, tais como: pulgões, curuquerê da couve, lagarta-rosca, lagarta-mede-palmo e traça-das-crucíferas (GALLO et al., 2002). Este último inseto é, muitas vezes, limitante para o cultivo de crucíferas em áreas tropicais em razão, principalmente, de seu ciclo curto e alto potencial reprodutivo, o que deter- mina número anual elevado de gerações (UlmeR et al., 2002).

O controle da traça-das-crucíferas é realizado geralmente com o uso de inseticidas. Ouso intensivo desses produtos selecionou populações resistentes aos diferentes princípios ativos comumente utilizados em seu controle (CASTELO BRANCO; GATEHOUSE 1997; Castelo Branco et al., 2001).

Produtos naturais extraídos de plantas constituem-se em fonte de substâncias bioativas compatíveis com programas de manejo integrado de pragas (MIP), o que pode reduzir os efeitos negativos ocasionados pela aplicação descontrolada de inseticidas

${ }^{2}$ Universidade Estadual de Goiás, Unidade de Universitária de Ipameri, Ipameri, GO, Brasil.

${ }^{3}$ Universidade Estadual Paulista, Faculdade de Ciências Agrárias e Veterinárias, Departamento de Fitossanidade, Jaboticabal, SP, Brasil. 
organossintéticos ao meio ambiente (MEDEIROS et al., 2005; Thuller et al., 2008; ZOTTI et al., 2010).

As plantas inseticidas são capazes de provocar inibição alimentar nos insetos, redução da motilidade intestinal, interferência na síntese do ecdisônio, inibição da biossíntese da quitina, deformações em pupas e adultos, redução na fecundidade, longevidade, esterilização, inibição na oviposição e mortalidade de formas imaturas e adultas (SCHMUTTERER, 1990; Mordue; BACKWell, 1993; Boiça Junior et al., 2005).

Algumas plantas inseticidas já foram avaliadas para ocontrole de P.xylostella. CHENetal.(1996) encontraram que extratos de Melia azedarach (L.) causaram 93,5\% de redução na oviposição de $P$. xylostella na concentração de $4 \%$. TorRes et al. (2001) verificaram que os extratos aquosos de Aspidosperma pyrifolium (Mart.), A. indica e Cissampelos aff. glaberrima (St. Hil.) reduziram a oviposição de $P$. xylostella, e que esta redução era diretamente correlacionada com o aumento das concentrações dos extratos dessas plantas e o efeito repelente se acentuava com a quantidade de substâncias bioativas extraídas e existentes em cada extrato. BoIçA JUNIOR et al. (2005) verificaram que os extratos aquosos de Sapindus saponaria L., Trichilia pallida SW, Enterolobium contortisilliquum (Vell.) Morong e Nicotiana tabacum L. causaram $100 \%$ de mortalidade das larvas dessa praga. Medeiros et al. (2005) constataram que os extratos de frutos de $S$. saponaria, e de E. contortisilliquum e de folhas de $T$. pallida, proporcionaram efeito deterrente na oviposição da praga, com índice de $100 \%$ de deterrência.

Portanto, tendo em vista a importância que representa ocultivo debrássicas eouso de extratos botânicos dentro do manejo integrado de pragas, este trabalho teve por objetivo determinar o efeito das plantas inseticidas A. indica (Nim), Sapindus saponaria (Sabão de soldado), Nim + Piretro + Rotenona, D. mollis (Faveira) e S. adstringens (Barbatimão) na oviposição e alimentação em lagartas de $P$. xylostella, bem como avaliar seus efeitos nos aspectos biológicos desse inseto.

\section{MATERIAL E MÉTODOS}

Os experimentos foram desenvolvidos no Laboratório de Entomologia da Universidade Estadual de Goiás, Unidade Universitária de Ipameri. Plantas de couve, B. oleracea var. acephala, 'Manteiga', semeadas em campo foram utilizadas para a criação da população de traça-das-crucíferas usadas nesse trabalho.

\section{Criação-estoque}

Para criação de P. xylostella, ovos deste inseto foram adquiridos do Laboratório de Resistência de Plantas a Insetos da FCAV - UNESP - Jaboticabal, SP. Lagartas recém-eclodidas foram confinadas em recipientes plásticos com dimensões $15 \times 10$ × 5 $\mathrm{cm}$, alimentadas com folhas de couve, previamente lavadas em água corrente.

Asfolhas foram trocadas semprequenecessárioaté que todos os insetos atingissem a fase de pupa. Essas foram coletadas diariamente e colocadas em tubos de vidrodefundochato, medindo $1 \mathrm{~cm}$ de diâmetro, fechadoscomfilmeplásticotransparentePVCcompequenos orifícios para circulação do ar. Após a emergência, os adultos foram coletados diariamente. Foi feita a sexagem e formados dez casais, que permaneceram confinadosem gaiolas plásticas transparentescirculares comumaabertura retangularvedadalateralmentecom malha fina de "nylon" para possibilitar a circulação do ar. A parte superior da gaiola continha um orifício circular onde foi colocada uma esponja embebida com uma solução de mel a 10\%, presa com uma rolha de pano tamponando tal abertura.

Dentro dessas gaiolas, foram colocados discos de folha de couve medindo $8 \mathrm{~cm}$ de diâmetro sobre papel filtro umedecido, sobre um copo plástico de 50 $\mathrm{mL}$ para a oviposição. Os discos foram substituídos diariamente e aqueles com as posturas foram acondicionados em placa de Petri até a eclosão das larvas, mantendo-se, então, os procedimentos já descritos.

\section{Obtenção do material vegetal}

As plantas inseticidas foram adquiridas na região de Ipameri, GO, ou junto a instituições de ensino e pesquisa.

O material vegetal foi mantido em estufa à temperatura de $40^{\circ} \mathrm{C}$ por 48 horas para secagem e posteriormente, moído, obtendo-se o pó, com granulação uniforme. $\mathrm{O}$ pó foi acondicionado em recipientes plásticos para posterior preparação dos extratos.

As concentrações dos extratos aquosos foram determinadas pela razão massa/volume $(\mathrm{m} / \mathrm{v})$. Foram misturados $10 \mathrm{~g}$ do pó do material vegetal em 100 mL de água destilada e o material ficou em repouso por 24 horas. Findo esse período, foram feitas filtragens com pano de malha fina para obtenção dos extratos. Após sua preparação, discos com aproximadamente $8 \mathrm{~cm}$ de diâmetro de folhas de plantas de couve foram imersos em cada extrato por 30 segundos e postos para secagem sobre papel toalha ao ar livre. O mesmo foi feito em água destilados para o tratamento testemunha. Após a secagem, os discos tratados foram transferidos para placa de Petri contendo papel filtro levemente umedecido com água destilada.

Efeito de planta inseticida na oviposição de $P$. xylostella

Em uma gaiola foram acondicionados os discos foliares dos seis tratamentos de forma circular, 
liberando-se em seguida 60 adultos (não sexados) de P. xylostella com até 12 horas de idade, proveniente da criação feita em laboratório. Estes foram mantidos por quatro dias para oviposição. Diariamente foi feita a contagem do número de ovos em cada tratamento e um novo disco foliar foi colocado na gaiola. $\mathrm{O}$ delineamento adotado foi o de blocos casualizados com seis tratamentos e seis repetições.

Teste de atratividade e não-preferência para alimentação de $P$. xylostella

Nos testes de atratividade com chance de escolha utilizaram-se placas de Petri (160 mm de diâmetro), forradas com papel filtro umedecido, onde foram colocados os discos foliares. Para obtenção dos discos foliares utilizou-se um vazador de $2,5 \mathrm{~cm}^{2}$ de área, retirando-se decada folha dois discos simetricamente opostos à nervura principal. Um disco foi utilizado para o teste e o outro como alíquota, a fim de determinar a massa seca consumida. Para isso, a sobra do disco e a alíquota foram desidratadas em estufa a $60^{\circ} \mathrm{C}$ durante 48 horas e foi obtida diferença entre a massa da alíquota e a massa da sobra do disco após o consumo das lagartas.

Foram liberadas no centro de cada arena seis lagartas de $2^{\circ}$ instar. A atratividade alimentar (número médio de lagartas atraídas para os discos foliares) foi avaliada aos 1, 3, 5, 10, 15 e 30 minutos e as 1, 2, 6, 12 e 24 horas após a liberação das lagartas. O delineamento foi blocos casualizados com seis tratamentos e 10 repetições.

Para o ensaio sem chance de escolha, utilizou-se a metodologia descrita anteriormente, entretanto, foi colocado apenas uma lagarta e um tratamento por placa de Petri (60 mm de diâmetro), em esquema inteiramente casualizados com seis tratamentos e 30 repetições.

Efeito de planta inseticida na biologia de $P$. Xylostella

Para observação do desenvolvimento de $P$. xylostella foram utilizados placas de Petri contendo folhas de couve-cv Manteiga, tratadas com as plantas inseticidas descritas anteriormente com as mesmas dosagens. Sobre cada folha foi colocada uma lagarta recém-eclodida e, em seguida, foram vedadas com filme PVC para evitar fuga delas. Essas placas foram mantidas no laboratório em condições do ambiente, sendo as folhas substituídas diariamente por outras tratadas. Quando as folhas foram trocadas, anotouse o número de larvas mortas. Tal procedimento foi adotado até que as larvas atingissem o estádio de pupa. As larvas sobreviventes foram pesadas aos 7 dias de idade e as pupas foram retiradas das placas 24 horas após a sua formação, pesadas e repostas na placa. Aí permaneceram até a emergência dos adultos.

As variáveis biológicas avaliadas foram: peso, duração do ciclo e viabilidade das fases larval e pupal. O delineamento estatístico adotado foi o inteiramente casualizado, com seis tratamentos e trinta repetições.

\section{Análise estatística}

Os dados dos experimentos foram analisados pelo teste de Tukey a $5 \%$ de probabilidade utilizando o software ESTAT.

\section{RESULTADOS E DISCUSSÃO}

Teste de atratividade e não-preferência para alimentação de $P$. xylostella

Para o teste de atratividade (número médio de lagartas atraídas para os discos foliares) com chance de escolha, verificam-se diferenças significativas para as avaliações dos 30 minutos até 24 horas, sendo no geral, os tratamentos menos atrativos a $A$. indica (Nim) e S. saponaria (Sabão de soldado) e os mais atrativos foram óleo de Nim + Piretro + Rotenona e a testemunha (Tabela 1).

Em relação à massa seca consumida (Tabela 1), os maiores valores foram observados nos tratamentos $\mathrm{Nim}+$ Piretro + Rotenota, seguido da testemunha, e o menos consumido nos tratamentos $A$. indica (Nim), S. saponaria (Sabão de soldado) e D. mollis (Faveira), o que sugere a presença de substâncias supressoras ou deterrentes nestas plantas, substâncias essas capazes de reduzir a alimentação da praga.

Nos testes de atratividade sem chance de escolha, verificaram-se diferenças significativas para as avalia-ções de 1 minuto até 24 horas após a liberação da praga, sendo os tratamentos menos atrativos, $A$. indica (Nim) e D. mollis (Faveira), e mais atrativos $\mathrm{Nim}+$ Piretro + Rotenota e a testemunha (Tabela 2).

Em relação ao consumo médio de $P$. xyllostella, constatou-se que os discos tratados com A. indica (Nim) foram os menos consumidos e a testemunha obteve a maior massa seca consumida.

\section{Efeito de plantas inseticidas na oviposição de} P. xylostella

O número médio de ovos de $P$. xylostella por disco de couve, nos diferentes tratamentos, diferiu significativamente entre si, sendo que os extratos $A$. indica (Nim), S. saponaria (Sabão de soldado), D. mollis (Faveira) e S. adstringens (Barbatimão) apresentaram efeito deterrente para a oviposição de adultos da praga com os menores valores médios (Tabela 3). 
Tabela 1 - Número médio de lagartas de P. xylostella atraídas e massa seca consumida (mg) por larvas, alimentadas com folhas de couve tratadas com plantas inseticidas, em teste com chance de escolha, Ipameri, 2008.

\begin{tabular}{lcccccc}
\hline \multirow{2}{*}{ Tratamentos } & \multicolumn{6}{c}{ Número médio de lagartas de P. xylostella atraídas ${ }^{1}$} \\
\cline { 2 - 7 } & $1 \mathrm{~min}$. & $3 \mathrm{~min}$. & $5 \mathrm{~min}$. & $10 \mathrm{~min}$. & $15 \mathrm{~min}$. & $30 \mathrm{~min}$. \\
\hline 1- Testemunha & 0,6 & 0,8 & 0,7 & 0,5 & 0,8 & $0,7 \mathrm{ab}$ \\
2- A. indica & 0,2 & 0,4 & 0,4 & 0,2 & 0,3 & $0,2 \mathrm{~b}$ \\
3- S. saponaria & 0,3 & 0,3 & 0,8 & 0,4 & 0,5 & $0,2 \mathrm{~b}$ \\
4- Nim + Piretro + Rotenona & 1,1 & 0,6 & 0,7 & 0,9 & 1,0 & $1,4 \mathrm{a}$ \\
5- D. mollis & 0,6 & 0,8 & 0,3 & 0,9 & 1,1 & $0,7 \mathrm{ab}$ \\
6- S. adstringens & 0,5 & 0,3 & 0,4 & 0,4 & 0,4 & $0,5 \mathrm{bc}$ \\
\hline C.V (\%) & 34,30 & 32,39 & 32,25 & 33,25 & $35,27^{\mathrm{NS}}$ & 28,50 \\
F. (Trat.) & $1,83^{\mathrm{NS}}$ & $1,11^{\mathrm{NS}}$ & $0,82^{\mathrm{NS}}$ & $1,57^{\mathrm{NS}}$ & $2,86^{*}$ & $5,28^{* *}$ \\
\hline \multirow{2}{*}{ Tratamentos } & \multicolumn{7}{c}{ Número médio de lagartas de $P . x y l o s t e l l a$ atraídas } & Consumo \\
& $1 \mathrm{~h}$ & $2 \mathrm{~h}$ & $6 \mathrm{~h}$ & $12 \mathrm{~h}$ & $24 \mathrm{~h}$ & $(\mathrm{mg} /$ larva) \\
\hline 1- Testemunha & $0,7 \mathrm{~b}$ & $0,8 \mathrm{~b}$ & $0,8 \mathrm{ab}$ & $0,4 \mathrm{ab}$ & $0,7 \mathrm{ab}$ & $7,89 \mathrm{ab}$ \\
2- A. indica & $0,1 \mathrm{c}$ & $0,1 \mathrm{c}$ & $0,1 \mathrm{c}$ & $0,00 \mathrm{~b}$ & $0,3 \mathrm{~b}$ & $4,93 \mathrm{~b}$ \\
3- S. saponaria & $0,2 \mathrm{bc}$ & $0,3 \mathrm{bc}$ & $0,3 \mathrm{bc}$ & $1,1 \mathrm{a}$ & $1,2 \mathrm{ab}$ & $5,78 \mathrm{~b}$ \\
4- Nim + Piretro + Rotenona & $1,4 \mathrm{a}$ & $1,7 \mathrm{a}$ & $1,4 \mathrm{a}$ & $1,3 \mathrm{a}$ & $1,7 \mathrm{a}$ & $12,13 \mathrm{a}$ \\
5- D. mollis & $0,7 \mathrm{~b}$ & $0,7 \mathrm{~b}$ & $0,8 \mathrm{ab}$ & $0,8 \mathrm{a}$ & $0,3 \mathrm{~b}$ & $5,18 \mathrm{~b}$ \\
6- S. adstringens & $0,5 \mathrm{bc}$ & $0,5 \mathrm{bc}$ & $0,8 \mathrm{ab}$ & $0,9 \mathrm{a}$ & $1,0 \mathrm{ab}$ & $6,41 \mathrm{ab}$ \\
\hline C.V (\%) & 28,50 & 29,08 & 28,96 & 34,05 & 38,90 & 42,19 \\
F. (Trat.) & $5,28^{* *}$ & $6,49^{* *}$ & $4,46^{* *}$ & $3,30^{*}$ & $2,28^{*}$ & $2,19^{*}$ \\
\hline
\end{tabular}

${ }^{1}$ Médias seguidas da mesma letra na coluna, não diferem estatisticamente entre si, pelo teste de Tukey ao nível de $5 \%$ de probabilidade. (Para análise os dados foram transformados em $\left.(x+0,5)^{1 / 2}\right)$.

**Significativo a $1 \%$ de probabilidade.

*Significativo a $5 \%$ de probabilidade.

NSNão significativo.

Tabela 2 - Número médio de lagartas de P. xylostella atraídas e massa seca consumida (mg) por larvas, alimentadas com folhas de couve tratadas com plantas inseticidas, em teste sem chance de escolha, Ipameri, 2008.

\begin{tabular}{|c|c|c|c|c|c|c|}
\hline \multirow{2}{*}{ Tratamentos } & \multicolumn{6}{|c|}{ Número médio de lagartas de P. xylostella atraídas ${ }^{1}$} \\
\hline & $1 \mathrm{~min}$. & $3 \mathrm{~min}$. & $5 \mathrm{~min}$. & 10min. & $15 \mathrm{~min}$. & $30 \mathrm{~min}$. \\
\hline 1- Testemunha & $0,90 \mathrm{a}$ & $0,90 \mathrm{a}$ & $0,90 \mathrm{a}$ & $0,97 \mathrm{a}$ & $0,93 \mathrm{ab}$ & $0,97 \mathrm{a}$ \\
\hline 2- A. indica & $0,27 \mathrm{~b}$ & $0,53 \mathrm{~b}$ & $0,60 \mathrm{~b}$ & $0,63 c$ & $0,60 \mathrm{~b}$ & $0,57 \mathrm{~b}$ \\
\hline 3- S. saponaria & $0,40 \mathrm{~b}$ & $0,77 \mathrm{a}$ & $0,73 \mathrm{ab}$ & $0,77 \mathrm{abc}$ & $0,70 \mathrm{ab}$ & $0,73 \mathrm{ab}$ \\
\hline 4- Nim + Piretro + Rotenona & $0,70 \mathrm{a}$ & $0,93 \mathrm{a}$ & $0,93 \mathrm{a}$ & $0,87 \mathrm{ab}$ & $0,87 \mathrm{ab}$ & $0,73 \mathrm{ab}$ \\
\hline 5- D. mollis & $0,50 \mathrm{~b}$ & $0,73 \mathrm{~b}$ & $0,73 \mathrm{ab}$ & $0,73 \mathrm{bc}$ & $0,73 \mathrm{ab}$ & $0,70 \mathrm{~b}$ \\
\hline 6- S. adstringens & $0,50 \mathrm{~b}$ & $0,83 \mathrm{ab}$ & $0,77 \mathrm{ab}$ & $0,70 \mathrm{bc}$ & $1,07 \mathrm{a}$ & $0,67 \mathrm{~b}$ \\
\hline C.V $(\%)$ & 22,46 & 18,68 & 19,27 & 19,02 & 24,00 & 20,80 \\
\hline F. (Trat.) & $8,52^{* *}$ & $3,86^{* *}$ & $2,62^{*}$ & $2,61^{*}$ & $1,91^{*}$ & $2,76^{*}$ \\
\hline \multirow{2}{*}{ Tratamentos } & \multicolumn{5}{|c|}{ Número médio de lagartas de P.xylostella atraídas } & Consumo \\
\hline & $1 \mathrm{~h}$ & $2 \mathrm{~h}$ & $6 \mathrm{~h}$ & $12 \mathrm{~h}$ & $24 \mathrm{~h}$ & (mg/larva) \\
\hline 1- Testemunha & $0,97 \mathrm{a}$ & $0,97 \mathrm{a}$ & $0,97 \mathrm{a}$ & $0,97 \mathrm{a}$ & $0,97 a$ & $13,39 \mathrm{a}$ \\
\hline 2- A. indica & $0,50 \mathrm{c}$ & $0,37 \mathrm{c}$ & $0,56 \mathrm{~b}$ & $0,63 \mathrm{bc}$ & $0,63 \mathrm{bc}$ & $4,05 \mathrm{c}$ \\
\hline 3-S. saponaria & $0,73 \mathrm{bc}$ & $0,80 \mathrm{ab}$ & $0,90 \mathrm{a}$ & $0,76 \mathrm{ab}$ & $0,67 \mathrm{ab}$ & $6,87 \mathrm{bc}$ \\
\hline 4- Nim + Piretro + Rotenona & $0,80 \mathrm{ab}$ & $0,83 \mathrm{ab}$ & $0,86 \mathrm{a}$ & $0,47 \mathrm{c}$ & $0,47 \mathrm{c}$ & $10,25 \mathrm{ab}$ \\
\hline 5-D. mollis & $0,70 \mathrm{bc}$ & $0,67 \mathrm{~b}$ & $0,46 \mathrm{~b}$ & $0,40 \mathrm{c}$ & $0,40 \mathrm{c}$ & $11,24 \mathrm{ab}$ \\
\hline 6- S. adstringens & $0,63 \mathrm{bc}$ & $0,63 \mathrm{~b}$ & $0,53 \mathrm{~b}$ & $0,40 \mathrm{c}$ & $0,40 \mathrm{c}$ & $5,27 \mathrm{~b}$ \\
\hline C.V $(\%)$ & 20,66 & 20,66 & 19,74 & 22,80 & 38,90 & 48,29 \\
\hline F. (Trat.) & $3,98^{* *}$ & $3,98^{* *}$ & $8,41^{* *}$ & $7,74^{* *}$ & $6,28^{* *}$ & $4,31^{* *}$ \\
\hline
\end{tabular}

${ }^{1}$ Médias seguidas da mesma letra na coluna, não diferem estatisticamente entre si, pelo teste de Tukey ao nível de 5\% de probabilidade. (Para análise os dados foram transformados em $\left.(\mathrm{x}+0,5)^{1 / 2}\right)$.

**Significativo a $1 \%$ de probabilidade.

*Significativo a $5 \%$ de probabilidade. 
Tabela 3 - Número médio de ovos de P. xyllostella em folhas de couve tratadas com plantas inseticidas, em teste com chance de escolha, Ipameri, 2008.

\begin{tabular}{lccccc}
\hline \multirow{2}{*}{ Tratamentos } & \multicolumn{4}{c}{ No médio de ovos/folha $^{1}$} & Total \\
\cline { 2 - 5 } & $24 \mathrm{~h}$ & $48 \mathrm{~h}$ & $72 \mathrm{~h}$ & $96 \mathrm{~h}$ & \\
\hline 1- Testemunha & $138,00 \mathrm{ab}$ & $144,33 \mathrm{a}$ & $124,83 \mathrm{a}$ & $149,67 \mathrm{a}$ & $556,83 \mathrm{a}$ \\
2- A. indica & $78,50 \mathrm{bc}$ & $96,70 \mathrm{abc}$ & $41,00 \mathrm{~b}$ & $64,50 \mathrm{~b}$ & $280,67 \mathrm{~b}$ \\
3- S. saponaria & $85,00 \mathrm{bc}$ & $60,50 \mathrm{bc}$ & $85,83 \mathrm{ab}$ & $82,00 \mathrm{ab}$ & $313,33 \mathrm{~b}$ \\
4- Nim + Piretro + Rotenona & $163,18 \mathrm{a}$ & $124,50 \mathrm{ab}$ & $146,83 \mathrm{a}$ & $138,83 \mathrm{a}$ & $573,33 \mathrm{a}$ \\
5- D. mollis & $89,00 \mathrm{bc}$ & $28,33 \mathrm{c}$ & $30,16 \mathrm{~b}$ & $83,67 \mathrm{ab}$ & $231,16 \mathrm{~b}$ \\
6- S. adstringens & $49,34 \mathrm{c}$ & $60,00 \mathrm{bc}$ & $96,00 \mathrm{ab}$ & $47,16 \mathrm{~b}$ & $252,50 \mathrm{~b}$ \\
\hline C.V (\%) & 31,84 & 41,46 & 46,36 & 32,03 & 24,33 \\
F. (Trat.) & $2,83^{*}$ & $2,88^{*}$ & $3,24^{*}$ & $3,17^{*}$ & $5,01^{* *}$ \\
\hline
\end{tabular}

${ }^{1}$ Médias seguidas da mesma letra na coluna, não diferem estatisticamente entre si, pelo teste de Tukey ao nível de 5\% de probabilidade. (Para análise os dados foram transformados em $\left.(\mathrm{x}+0,5)^{1 / 2}\right)$.

*Significativo a $5 \%$ de probabilidade.

Tabela 4 - Médias do peso larval e pupal, período larval e pupal, longevidade de adultos, ciclo total e viabilidade larval e pupal de P. xyllostella em folhas de couve tratadas com plantas inseticidas.

\begin{tabular}{|c|c|c|c|c|}
\hline \multirow{2}{*}{ Tratamentos } & \multicolumn{4}{|c|}{ Parâmetros Avaliados } \\
\hline & Peso larval (mg) & Peso Pupal (mg) & Período Larval (dias) & Período Pupal (dias) \\
\hline 1- Testemunha & $4,61 \mathrm{ab}$ & $4,61 \mathrm{ab}$ & $8,14 \mathrm{~b}$ & $3,4 \mathrm{~b}$ \\
\hline 2- A. indica & $1,97 \mathrm{c}$ & $2,78 b$ & $8,08 \mathrm{~b}$ & -2 \\
\hline 3- S. saponaria & $1,94 \mathrm{c}$ & $3,62 b$ & $8,42 \mathrm{~b}$ & $4,13 \mathrm{a}$ \\
\hline 4- Nim + Piretro + Rotenona & $2,52 b c$ & $4,05 \mathrm{ab}$ & $8,40 \mathrm{~b}$ & $3,73 \mathrm{ab}$ \\
\hline 5- D. mollis & $5,37 \mathrm{a}$ & $5,9 \mathrm{a}$ & 8,06 a & $3,60 \mathrm{~b}$ \\
\hline 6- S. adstringens & $1,55 c$ & $3,78 \mathrm{ab}$ & $8,09 \mathrm{~b}$ & $4,13 \mathrm{a}$ \\
\hline C.V $(\%)$ & 47,00 & 33,69 & 12,08 & 17,51 \\
\hline F. (Trat.) & $3,57^{* *}$ & $3,57^{* *}$ & $5,02^{* *}$ & $3,6^{*}$ \\
\hline \multirow[b]{2}{*}{ Tratamentos } & \multicolumn{4}{|c|}{ Parâmetros Avaliados } \\
\hline & $\begin{array}{c}\text { Longevidade } \\
\text { (dias) }\end{array}$ & Ciclo total (dias) & Viabilidade Larval (\%) & $\begin{array}{c}\text { Viabilidade } \\
\text { Pupal (\%) }\end{array}$ \\
\hline 1- Testemunha & $4,06 \mathrm{ab}$ & 15,2 & $100,00 \mathrm{a}$ & $78,00 \mathrm{a}$ \\
\hline 2- A. indica & - & - & - & - \\
\hline 3- S. saponaria & $3,33 \mathrm{bc}$ & 15,4 & $40,00 \mathrm{c}$ & $16,00 \mathrm{c}$ \\
\hline 4- Nim + Piretro + Rotenona & $3,26 \mathrm{c}$ & 15,67 & $86,00 \mathrm{~b}$ & $30,00 \mathrm{c}$ \\
\hline 5- D. mollis & $4,06 \mathrm{ab}$ & 15,80 & $82,00 \mathrm{~b}$ & $44,00 \mathrm{~b}$ \\
\hline 6- S. adstringens & $4,13 \mathrm{a}$ & 16,26 & $88,00 \mathrm{~b}$ & $52,00 \mathrm{~b}$ \\
\hline C.V (\%) & 25,32 & 9,63 & 43,61 & 52,73 \\
\hline F. (Trat.) & $3,08^{*}$ & $1,09^{\mathrm{NS}}$ & $21,90^{* *}$ & $13,68^{* *}$ \\
\hline
\end{tabular}

${ }^{1}$ Médias seguidas da mesma letra não diferem estatisticamente entre si, pelo teste de Tukey ao nível de 5\% de probabilidade. (Para análise os dados foram transformados em $\left.(\mathrm{x}+0,5)^{1 / 2}\right)$.

**Significativo a $1 \%$ de probabilidade.

*Significativo a $5 \%$ de probabilidade.

NSNão significativo.

${ }^{2}$ Todas as lagartas morreram (variância nula).

Essa deterrência também foi constatada por outros autores em outras culturas e pragas, como COUDRIET et al. (1985), que trataram folhas de algodão com extrato aquoso de sementes de $A$. indica (Nim) e observaram redução na oviposição de B. tabaci.

Apesar dealgumas plantas, relatadas na literatura como redutoras de oviposiçãonão tereminfluenciado a de P.xylostella, não devem ser descartadas. Devemse testar outros meios de extração dos princípios ativos existentes nas plantas, pois Roel et al. (2000) verificaram diferentes resultados entre os diversos solventes utilizados.

Efeito de planta inseticida na biologia de $P$. xylostella 
$\mathrm{Na}$ avaliação referente aos estudos dos aspectos biológicos de P. xylostella, alimentada com os discos foliares dos diferentes tratamentos larvas alimentadas com os extratos de A. indica (Nim), S. saponaria (Sabão de soldado) e S. adstringens (Barbatimão) apresentaram menor peso (Tabela 4). Em relação ao peso médio de pupas houve diferença significativa entre os tratamentos, sendo que as tratadas com extrato de D. mollis (Faveira) apresentaram os maiores valores e as alimentadas com A. indica (Nim) e $S$. saponaria (Sabão de soldado) tiveram os menores valores (Tabela 4 ).

A duração da fase larval de P. xylostella foi afetada pelos extratos aquosos das espécies vegetais. As larvas que se alimentaram de discos foliares tratados com extrato de D. mollis (Faveira) tiveram uma redução dessa fase.

De acordo com TORRES et al. (2001), o prolongamento da fase larval de P. xylostella, adicionalmente à mortalidade da fase larval, mediante aplicação de extratos vegetais é muito importante em campo, pois aumentará o tempo de exposição da praga aos inimigos naturais, bem como o tempo médio de cada geração, reduzindo o crescimento populacional da praga.

Em relação à viabilidade larval, as larvas que se alimentaram de folhas de couve contendo o extrato de A. indica (Nim) apresentaram alto índice de mortalidade com poucas larvas atingindo a fase de pupa. No entanto, havia uma alta quantidade de pupas deformadas, e, consequentemente, não emergiram adultos nesse tratamento.

MORDUE; BlACKWELL (1993) também relataram que insetos tratados ou alimentados com azadiractina, inseticida regulador de crescimento de origem vegetal, apresentam inibição de crescimento, má-formação, prolongamento da fase larval e até morte das lagartas algumas horas após o tratamento.

Os extratos de S. saponaria (Sabão de soldado) e S. adstringens (Barbatimão) provocaram maior prolongamento do período pupal (Tabela 4), consequentemente, em condições de campo, os insetos teriam menores gerações ao longo do ano, reduzindo assim o dano nesta cultura.

Para viabilidade pupal foi observada uma mortalidade em $100 \%$ das lagartas para o tratamento $A$. indica (Nim). Os tratamentos S. saponaria (Sabão de soldado) e Nim + Piretro + Rotenona apresentaram os melhores índices entre os demais. Observou-se a influência entre o peso e a mortalidade de pupa, evidenciandoqueos extratosqueocasionaram menor peso de pupa proporcionaram maiores mortalidades desta fase (Tabela 4).

Bezerril; CARneiro (1992), estudando os efeitos de extratos vegetais em relação $P$. xylostella, verificaram reduções na emergência de adultos, da ordem de $86,6 \%$ para M. azedarach, $43,6 \%$ para Datura stra- monium (L.), 71,6\% para Sapindus spp., 87,8\% para Marabilis jalapa e 60,0\% para C. ambrosioides, quando comparados à testemunha.

Em relação à longevidade media de adulto, os que se alimentaram de folhas de couve tratadas com o extrato de S. adstringens (Barbatimão) foram mais longevos em relação aos demais e a menor para Nim + Piretro + Rotenona (Tabela 4). Para a avaliação do ciclo total de P. xylostella, não houve diferença significativa entre os extratos botânicos.

\section{CONCLUSÕES}

No teste com chance de escolha, os tratamentos A. indica (Nim), S. saponaria (Sabão de soldado) e D. mollis (Faveira) proporcionaram menor oviposição por adultos e alimentação de lagartas de P. xylostella.

No teste sem chance de escolha, A. indica (Nim) e S. saponaria (Sabão de soldado) reduziram a alimentação das lagartas de P. xylostella.

O desenvolvimento do inseto foi afetado pela aplicação de A. indica (Nim) e S. saponaria (Sabão de soldado).

\section{REFERÊNCIAS}

BEZERRIL, E.F.; CARNEIRO, J.S. Manejo integrado da traça do repolho, Plutella xylostella (L.) no Planalto do Ibiapaba-Ceará. Horticultura Brasileira, v.10, n.1, p.49, 1992.

BOIÇA JUNIOR, A.L.; MEDEIROS, C.A.M.; TORRES, A.L.; CHAGAS FILHO, N.R. Efeito de extratos aquosos de plantas no desenvolvimento de Plutella xylostella (L.) (Lepidoptera: Plutellidae) em couve. Arquivos do Instituto Biológico, São Paulo, v.72, n.1, p.45-50, 2005.

CASTELO BRANCO, M.; GATEHOUSE, A.G. Insecticide resistance in Plutella xylostella (Lepidoptera: Yponomeutidae) in the Federal District, Brazil. Anais da Sociedade Entomológica do Brasil, v.26, n.1, p.75-79, 1997.

CASTELO BRANCO, M.; FRANÇA, F.H.; MEDEIROS, M.A.; LEAL, J.G.T. Uso de inseticidas para o controle da traça-do-tomateiro e traça-das-crucíferas: um estudo de caso. Horticultura Brasileira, v.19, n.1, p.60-63, 2001.

CHEN, C.; CHANG, S.; CHENG, L.; HOU, R.F. Deterrent effect of the chinaberry extract on oviposition of the diamondback moth, Plutella xylostella (L.) (Lepidoptera: Yponomeutidae). Journal Applied Entomology, v.120, p.165-169, 1996.

COUDRIET, D.L.; PRABHAKER, N.; MEYERDIRK, D.E. Sweetpotato whitefly (Homoptera: Aleyrodidae): effects of neem-seed extract on oviposition and immature stages. Environmental Entomology, v.14, n.6, p.776779, 1985. 
FILGUEIRA, F.A.R. Novo manual de olericultura: agrotecnologia moderna na produção e comercialização de hortaliças. 3.ed. Viçosa-MG: UFV, 2008. 412 p.

GALLO, D.; NAKANO, O.; SILVEIRA NETO, S.; BAPTISTA, G.C.; BERTI FILHO, E.; PARRA, J.R.P.; ZUCCHI, R.A.; ALVES, S.B.; VENDRAMIM, J.D.; MARCHINI, L.C.; LOPES, J.R.S.; OMOTO, C.

Entomologia agrícola. FEALQ, 2002. 920p.

MEDEIROS, C.A.M.; BOIÇA JUNIOR, A.L.; TORRES, A.L.T. Efeito de extratos aquosos de plantas na oviposição da traça-das-crucíferas, em couve. Bragantia, v.64, n.4, p.227-232, 2005.

MORDUE, A.J.; BLACKWELL, A. Azadirachtin: an update. Journal Insect of Physiology, v.39, n.11, p.903-924, 1993.

ROEL, A.R.; VENDRAMIM, J.D.; FRIGHETTO, R.T.S.; FRIGHETTO, N. Atividade tóxica de extratos orgânicos de Trichilia pallida Swartz (Meliaceae) sobre Spodoptera frugiperda (J. E. Smith). Anais da Sociedade Entomologica do Brasil, v.29, n.4, p.799-808, 2000.

SCHMUTTERER, H. Properties and potential of natural pesticides from the neem tree, Azadirachta indica. Annual Review of Entomology, v.35, n.2, p.217-297, 1990.
THULLER, R.T.; BORTOLI, S.A.; GOULART, R.M.; PEREIRA-VIANA, C.L.T.; PRATISSOLI, D. Interação tritrófica e influência de produtos químicos e vegetais no complexo: brássicas $\mathrm{x}$ traça-das-crucíferas $\mathrm{x}$ parasitóides de ovos. Ciência e Agrotecnologia, v.32, n.4, p.11541160, 2008.

TORRES, A.L., BARROS, R.; OLIVEIRA, J.V. Efeito de extratos aquosos de plantas no desenvolvimento de Plutella xylostella (L.) (Lepidoptera: Plutellidae). Neotropical Entomology, v.30, n.1, p.151-156, 2001.

ULMER, B., GILLOTT, C., WOODS, C., ERLANDSON, M. Diamondback moth, Plutella xylostella (L.), feeding and oviposition preferences on glossy and waxy Brassica rapa (L.) lines. Crop Protection, v.21, n.4, p.327-331, 2002.

ZOTTI, M.J., GRÜTZMACHER, A.D., GRÜTZMACHER, D.D., CASTILHOS, R.V., MARTINS, J.F.S. Seletividade de inseticidas usados na cultura do milho para ovos e ninfas do predador Doru lineare (Eschscholtz, 1822) (Dermaptera: Forficulidae). Arquivos do Instituto Biológico, São Paulo, v.77, n.1, p.111-118, 2010. Disponível em <http://www.biologico.sp.gov.br/docs/arq/ v77_1/zotti.pdf>. Acesso em: 12 abr. 2010

Recebido em 20/4/10

Aceito em 18/1/11 